Para além da superfície da imagem: disputa de narrativa por fotógrafos da África

Marcela Chaves Barino do Valle

\author{
Patrícia Saldanha
}

Artigo recebido em: 03/07/2019

Artigo aprovado em: 08/06/2020 


\title{
Para além da superfície da imagem: disputa de narrativa por fotógrafos da África
}

Beyond the image surface: narrative dispute by photographers from Africa

\author{
Marcela Chaves Barino do Valle*
}

Patrícia Saldanha**

\begin{abstract}
Resumo: Novas visualidades sobre o continente africano podem ser constatadas no perfil do Instagram 'Everyday África', a partir das narrativas das publicações de dois de seus proeminentes fotógrafos: o ganês Acquah e a nigeriana Emezi. Ao observar a transcendência da superficie aparente de imagens que disputam representações, a análise de conteúdo das postagens auxiliou metodologicamente a refletir sobre a quebra dos pressupostos raciais proposta por Hall, com enfoque na perspectiva dos filósofos africanos Hountondji (2008) e Appiah (1997).
\end{abstract}

Palavras-chave: Instagram 'Everyday África'. Imagem $e$ representação. Narrativas africanas. Fotografia documental.

\begin{abstract}
New visualities about the African continent can be found in the Instagram profile 'Everyday Africa', from the narratives of the publications of two of its prominent photographers: Ghanaian Acquah and Nigerian Emezi. When observing the transcendence of the apparent surface of images that dispute representations, the content analysis of the posts helped methodologically to reflect on the breakdown of racial assumptions proposed by Hall, focusing on the perspective of the African philosophers Hountondji (2008) and Appiah (1997).
\end{abstract}

Keywords: Instagram 'Everyday Africa'. Image and representation. African narratives. Documentary photography.

* Doutoranda em Comunicação e Cultura pela Universidade Federal do Rio de Janeiro. Professora de Fotografia Documental no ECDD-Infnet.

** Doutora em Comunicação e Cultura pela Universidade Federal do Rio de Janeiro. Professora do Programa de Pós-Graduação em Mídia e Cotidiano da Universidade Federal Fluminense. 


\section{Introdução}

A imagem da África construída pelo e para o Ocidente precisa ser remodelada, não somente por vozes que falam de dentro, mas que falam para dentro do continente. Uma nova orientação aos Estudos Africanos é o que almeja o filósofo beninense Paulin Hountondji (2008) ao propor a crítica à própria produção de conhecimento realizada por africanos que, ao invés de se voltarem para demandas externas, devem concretizar e fortalecer seus próprios debates endógenos e autônomos. Similar percurso é percebido no âmbito da fotografia documental, onde a disputa é contra as construções mistificadas da mídia global que promovem uma visão limitada e distorcida da então pluralidade de cenas e situações possíveis no amplo e diversificado continente africano.

Nesse sentido, o presente artigo, que resulta da ampla investigação realizada para a dissertação de mestrado, segue no objetivo de analisar a potência política da fotografia em disputas por representações e imagens de mundo. O objeto da pesquisa que estruturou o presente artigo foi o projeto fotográfico Everyday África, já o corpus selecionado foi o perfil do Instagram, principal meio de atuação do projeto, com recorte no ano de 2016, ano de intensas atividades e consolidação de seus quatro anos de existência. Isso incluiu a atuação de 23 fotógrafos e um total de 836 fotografias analisadas. Seguindo a natureza teórica da pesquisa, a

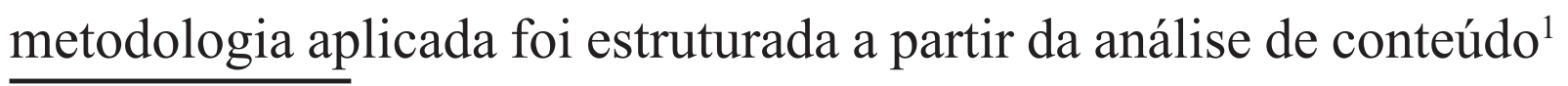
1 Uma análise estrutural do projeto observou o olhar por trás da imagem, detectando dois tipos de fotógrafos atuantes, os nômades, com um olhar de fora que está de passagem, e os nativos, um olhar de dentro que fala de si e que no ano de 2016 teve predomínio de atuação no Instagram do EverydayAfrica: 60\% dos fotógrafos que publicaram 77,9\% das imagens. Concluiu-se, portanto, nesta etapa, 
e fundamentada por extensa pesquisa bibliográfica.

Nessa acepção, o ponto de partida da reflexão teórica aqui proposta incide sobre a contestação de dois pressupostos que se entrecruzam na concepção das representações de mundo e que devem ser descontruídos. Tanto a designação da fotografia documental como cópia fidedigna do real quanto a definição biológica de raça precisam ser entendidas não apenas como processos naturais, mas pela perspectiva das convenções sociais tão naturalizadas na vida cotidiana. Ambas as premissas acarretam em uma percepção distorcida do 'outro', frequentemente aparente na superfície ${ }^{2}$ de imagens estereotipadas em reportagens espetaculares da mídia tradicional.

Como fio condutor, segue o argumento de Stuart Hall (2013) sobre a necessidade de derrubar os "pressupostos do senso comum e formas cotidianas de falar de raça e de produzir sentido sobre raça na sociedade de hoje". Completando esse pensamento, com atenção especial à fotografia, o artigo se alinha com a proposição de Allan Sekula de que a verdade presumida na imagem técnica não passa de que a visão e a voz compartilhada pelo Everyday África é da e para a África. Posteriormente, uma análise quantitativa da representatividade da voz africana na África representada concluiu que a documentação abarca, de forma desigual, $74,13 \%$ da extensão territorial do continente. E através de análise temática e formal detectou-se que inclusive a especificidade da vida cotidiana é documentada com distinto enfoque pelos dois grupos de fotógrafos. Enquanto os estrangeiros se concentram em evidenciar uma África feliz, os nativos exploram mais a fundo o cotidiano das cidades africanas, incluindo seus problemas, ao adicionarem suas vozes às visões compartilhadas.

$2 \mathrm{O}$ sentido aqui pretendido com o termo superfície se opõe à profundidade $\mathrm{e}$ se traduz na superficialidade das mesmas imagens estereotipadas presentes em reportagens da mídia tradicional. Tanto a concepção de Deleuze da arte da superfície, quanto a de Foucault sobre a superfície de inscrição, percorrem outros caminhos e não se opõem à profundidade, como explica Deleuze em Conversações (1992), mas à interpretação. 
um mito, uma convenção social que tem por função tornar o discurso fotográfico supostamente transparente. Como método, parte-se da problematização do que se torna conhecido por intermédio de fotografias documentais em sua dimensão cartorial, para a necessária contestação dos discursos fotográficos presentes, em especial, na mídia de massa. Tal desconstrução direciona o exame para o perigo das mesmas histórias fabricadas e naturalizadas frente à ausência de outras perspectivas e, consequentemente, possibilidades de existência. Ainda no trajeto da desconstrução, o debate se volta para a urgente quebra de pressupostos biológicos raciais e a iluminação de sua finalidade; para então, por meio de análise documental e teórica, observar as alternativas presentes em narrativas híbridas, autorais e nativas que objetivam dar visibilidade a uma nova visualidade da África possível na atualidade.

É nesta angulação que novas visualidades e relatos endógenos apostam na formação de um novo modo de olhar, fruto de uma outra forma de narrar, que tem por objetivo ultrapassar o aparente e dar a devida relevância às histórias e especificidades da vida cotidiana em diferentes localidades do continente africano. Portanto, com o intuito de observar as críticas e as possibilidades que tais narrativas nativas iluminam, serão observadas fotografias de dois documentaristas africanos, o ganês Nana Kofi Acquah e a nigeriana Yagazie Emezi, onde ambos se dispõem a ir além da superfície de imagens e cor de peles para, na sequência, mergulhar em questões próprias a África. 


\section{O Mito da Verdade Fotográfica}

A fotografia documental detém a incumbência de revelar aos homens fragmentos visuais do mundo real. Desde o surgimento da imagem técnica, espectadores se habituaram a conhecer e passaram a se familiarizar com notícias que chegam sobre terras distantes, ou nem tanto, por intermédio da sensibilidade e da informação contidas nas mensagens fotográficas em meios de comunicação de massa. Em sua função pública, a narrativa fotográfica compõe uma dimensão visível da realidade que orienta, em grande medida, imaginários, opiniões, gostos e valores acerca dos assuntos abordados. Portanto, as fotografias apresentadas na mídia subsidiam a construção cotidiana do conhecimento social e da imagem de mundo; todavia, elas consolidam uma visão que não necessariamente corresponde à realidade local.

Em quase dois séculos de existência, a imagem técnica já serviu para fins de esclarecimento e de conformação social. Walter Benjamin já alertava para a talvez inevitável ambiguidade de documentos culturais, constatando que "nunca houve um documento da cultura que não fosse simultaneamente um documento da barbárie. $\mathrm{E}$, assim como o próprio bem cultural não é isento de barbárie, tampouco o é o processo de transmissão em que foi passado adiante" (BENJAMIN, 2012, p. 245). Deste modo, Sekula propõe que se trabalhe para a compreensão crítica de representações fotográficas estando elas dentro de um discurso que é determinado cultural, política e economicamente, por forças externas que gerenciam e dirigem, sorrateiramente, tanto a produção quanto o consumo de imagens. 
Em meio ao panorama descrito, a questão primordial deve se voltar para como elucidar processos constitutivos que não costumam ser percebidos de forma explícita, sendo seus discursos certificados pelo poder cartorial convencionado à imagem técnica. Para compreender que visão de mundo é essa que a fotografia documental acaba por corroborar é preciso, primeiro, desconstruir a forma como ela tem sido usualmente percebida desde suas origens, bem como as implicações correlacionadas a seus usos e funções ao longo dos tempos.

Devido à sua gênese mecânica, a imagem técnica foi por muitos anos subentendida como uma cópia exata, reflexo perfeito de mundo. Quando a fotografia assume o lugar da pintura na função de recriar o real com uma fidedignidade até então inatingível, a nitidez da presença do artista, de um lado, corrobora a percepção ilusória de uma ausência autoral, do outro. Assim a fotografia passa a ser considerada, além de objetiva por sua exatidão mecânica, neutra pela suposta ausência da mão de seu criador. Além do mais, a imagem técnica, como declara Dubois, "não pode mentir. Nela a necessidade de "ver para crer" é satisfeita. A foto é percebida como uma espécie de prova, ao mesmo tempo necessária e suficiente, que atesta indubitavelmente a existência daquilo que mostra" (DUBOIS, 1993, p. 25). Por conseguinte, o espectador é instruído a olhar para as representações como olha para a realidade e a aceitálas de forma acrítica. Um poder cartorial de verdade é auferido à imagem fotográfica e sua percepção se mantém atrelada a esse efeito naturalista por todo séc. XIX e meados do séc. XX. No entanto, mesmo na atualidade, a neutralidade e objetividade convencionada à fotografia documental ainda se perpetua no senso comum da vida mundana. 
Para alterar essa percepção, o primeiro ponto consiste em perceber que mesmo a fotografia documental, fiel ao mundo que representa, não deixa de ser uma construção. O recorte visual de um instante do real que corresponde a escolhas, intencionalidade e à concepção de mundo de seu autor. Contudo, os processos constitutivos da mensagem fotográfica não cessam em seu criador, o que leva ao segundo ponto. Constatar que a imagem técnica, em meio ao seu propósito de comunicar algo a alguém, não se apresenta sozinha e tampouco é compreendida independente de outros sistemas de linguagem. Diante da soma de textos e contextos, cargas de significância interferem na percepção das híbridas narrativas fotográficas e podem, desta forma, manter ou alterar por completo seus significados primordiais.

Sekula argumenta que a própria compreensão do discurso fotográfico "depende de alguma matriz externa de condições e pressuposições para sua legibilidade" (SEKULA, 1982, p. 85, tradução nossa) $)^{3}$. Ou seja, o significado das fotografias documentais acaba por ser determinado pelo texto que a significa e pelo contexto onde esta se encontra. A função de representar fatos e personagens, contar pequenas ou grandes histórias, testemunhar e comprovar acontecimentos em curso, pode servir aos mais diversos desígnios. Por isso, o crítico americano se recusa a pensar a fotografia apenas teoricamente, separada da vida mundana e das funções a ela demandadas. $\mathrm{O}$ discurso fotográfico é utilizado para várias "tarefas representacionais" (SEKULA, 1984, p. 5), que acabam a serviço de múltiplas finalidades.

3"Amessage that depends on some external matrix of conditions and presuppositions for its readability. That it, the meaning of any photographic message is necessarily context-determined" (SEKULA, 1982, p. 85). 
Desta forma, Sekula conclui que o poder de verdade presumido à fotografia não passa de um mito, uma convenção social que tem por objetivo naturalizar a função do discurso onde ela se encontra inserida. A fotografia serve, assim, para corroborar a informação construída e descartar qualquer dúvida sobre seu conteúdo. Em outras palavras, a objetividade convencionada à fotografia documental induz a um não-questionamento não apenas sobre o que é visto na imagem, mas inclusive sobre as histórias adjacentes. A credibilidade não se mantém restrita à imagem técnica, mas perpassa pelo conhecimento que ela engendra, encobrindo tanto a codificação linguística que a significa, quanto a produção discursiva e os meios nos quais ela se encontra inserida.

Discursos midiatizados que declaram retratar com objetividade o que acontece pelo mundo acabam apenas por revelar as mesmas regiões e temáticas enquadradas dentro de um padrão pré-fabricado do que se espera de fotografias em notícias e reportagens. Desta forma, a imagem técnica acaba refém de padrões de noticiabilidade, intencionalidades e censuras que, ou antecipam e delimitam o ato criador do fotógrafo, ou a submetem a adições de textos e contextos com significados subjacentes, por vezes contraditórios, à mensagem visual primordial. Em contrapartida, múltiplas são as cenas que não chegam a estampar as capas de jornais ou revistas, e ainda há as que nem são materializadas e o fato tende a se perder na fluidez do tempo passado, deixando lacunas no percurso.

Além de sua gênese mecânica, dois outros atributos essenciais devem ser considerados: sua polissemia, disposição natural da imagem fotográfica em assumir outros sentidos ou significâncias; e seu caráter fragmentário, em detrimento das construções narrativas 
que tendem a ultrapassar seus significados originais. $\mathrm{Na}$ vida cotidiana, por mais que a fotografia carregue a incumbência de prova do real, sua mensagem dificilmente abrange todas as perspectivas possíveis sobre o assunto e tampouco compreende a totalidade de uma situação, cultura ou sociedade. Fotografias revelam apenas pequenas fatias de uma história que se pretende visível, são recortes singulares no espaço e no tempo. Assim como os acontecimentos são fragmentos da história, as fotografias são micro partes de um mundo que se revela, um mundo plural, composto por histórias sem fim.

Mesmo assim, ao se constituir uma narrativa, é comum que se amplie o olhar para além do que está representado no referente, para que este fale mais e construa um todo imaginário de uma história revelada. Existe uma generalidade presumida em discursos que ambicionam contar a totalidade de uma situação e incorrem no risco de obscurecer o caráter parcial tanto da fotografia quanto da própria história. $\mathrm{O}$ ponto que se pretende elucidar aqui é o de que uma fotografia tida como prova do real não requer outras imagens, nem incita à dúvida sobre o que está - ou não está - sendo abarcado por aquela cena. Cabe à fotografia atestar os acontecimentos, com seu caráter probatório e documental, tornando-se, portanto, arquivo da história; só que uma história construída sobre alguns fragmentos aparentes de real, que costumam ser subentendidos como a (única) realidade.

Hall discorre sobre o assunto ressaltando a incoerência em se mostrar apenas imagens já aguardadas, pois correspondentes ao paradigma midiático, argumentando que desse modo não se produzem novos conhecimentos, mas apenas "reconhecimentos do mundo como nós já aprendemos a nos apropriar" (HALL, 1981, 
p. 239, tradução nossa) $)^{4}$. Além de não apresentar nem informar sobre nada de novo, tais imagens tendem a reforçar estereótipos que culminam na cristalização de um conhecimento mistificado de mundo.

\section{O perigo da única história $X \mathrm{O}$ poder das alternativas}

Diante da repetição constante de cenas de violência e miséria, amplificadas pela ausência de outras representações simbólicas, consolida-se no imaginário social uma imagem mistificada de um continente distante, de um povo exótico ou de uma classe subalterna. Pessoas que desconhecem outras realidades, passam a julgá-las pelo que 'conhecem' através da mídia.

As representações estão destinadas a servir como arquétipos a orientar percepções sobre o que existe ou acontece em regiões vizinhas ou longínquas do globo, induzindo o que os indivíduos sentem ou pensam a respeito de uma infinidade de assuntos e situações, inclusive, no que diz respeito a quem são (eles mesmos e os outros) no mundo. Ao problematizar sobre o sistema de representação, Hall (2016) o situa no cerne do processo de produção e compartilhamento de sentido pelos membros de determinada cultura. $\mathrm{O}$ autor jamaicano afirma que somente somos "capazes de nos comunicar porque compartilhamos praticamente os mesmos mapas conceituais e, assim, damos sentido ou interpretamos o mundo de forma mais ou menos semelhante. Isso é, de fato, o que significa pertencer "à mesma cultura"” (HALL, 2016, p. 36). Portanto, é de

4 "The ideological concepts embodied in photos and texts in a newspaper, then, do not produce new knowledge about the world. They produce recognitions of the world as we have already learned to appropriate it” (HALL, 1981, p. 239). 
acordo com esses mapas mentais, seus preceitos e valores atribuídos, que o indivíduo é capacitado a ver e a interpretar o mundo.

No entanto, a massificação de uma mesma tipologia de histórias recai no consequente apagamento de outras perspectivas possíveis. O pior em se criar e solidificar estereótipos é o consequente apagamento das outras possibilidades de narrativas e representações. Como um grito de alerta para o perigo de uma única história, a escritora nigeriana Chimamanda Adichie discursa sobre a força dos contos infantis, ingleses ou americanos, que lia quando criança. Ainda bem nova, com seus 7 anos, Adichie começou a escrever suas próprias narrativas, como descreve:

Eu escrevi exatamente o tipo de histórias que eu estava lendo: todos os meus personagens eram brancos e de olhos azuis, jogavam na neve, comiam maçãs e conversavam muito sobre o clima, como era lindo que o sol tivesse saído. Agora, isso apesar do fato de eu ter vivido na Nigéria. Eu nunca estive fora da Nigéria. Não tínhamos neve, comemos mangas e nunca conversamos sobre o clima, porque não havia necessidade de fazê-lo (ADICHIE, 2009, tradução nossa) ${ }^{5}$.

Sua declaração configura a força com que as histórias impregnam o imaginário. E como a presença exclusiva de determinados pontos de vista, frente à ausência de uma multiplicidade de outros contos e representações visuais, pode impingir uma falsa noção de que somente aquelas meninas brancas de olhos azuis podem

5 "I wrote exactly the kinds of stories I was reading: all my characters were white and blue-eyed, they played in the snow, they ate apples, and they talked a lot about the weather, how lovely it was that the sun had come out. Now, this despite the fact that I lived in Nigeria. I had never been outside Nigeria. We didn't have snow, we ate mangoes, and we never talked about the weather, because there was no need to" (ADICHIE, 2009). 
habitar as fábulas infantis. Apenas quando teve acesso aos escritores africanos que a autora pôde realizar "que as pessoas gostam de mim, as meninas com a pele da cor de chocolate, cujos cabelos tortuosos não podiam formar rabo de cavalo, também poderiam existir na literatura" (ADICHIE, 2009, tradução nossa) ${ }^{6}$. Este relato delineia as consequências mistificadoras no imaginário social que a massificação de apenas uma tipologia de histórias tende a acarretar.

Todavia, a própria Adichie (2017) afirma o poder incalculável das alternativas para disputar os sentidos pré-existentes. Diante da enxurrada de estereótipos presentes cotidianamente nos discursos midiáticos, nos livros didáticos, nos filmes hollywoodianos, tornase possível se contrapor aos estereótipos se alternativas estiverem disponíveis. Da mesma forma com que algumas histórias podem servir para menosprezar e distanciar, outras histórias podem valorizar e aproximar os homens. Em meio a novas visualidades e histórias narradas, somadas a desconstrução de velhos pressupostos, que a percepção do outro pode transpor a superfície de imaginários estereotipados para mergulhar nas especificidades da vida cotidiana.

\section{O Mito da Raça}

De ascendência argelina e francesa, o filósofo Franz Fanon ${ }^{7}$ argumenta "que a maioria da estereotipagem racial e a violência surgiram a partir da recusa do "Outro" branco em reconhecer "do

6 "I realized that people like me, girls with skin the color of chocolate, whose kinky hair could not form ponytails, could also exist in literature" (ADICHIE, 2009).

7 Franz Fanon foi consagrado influente pensador do século XX nos temas da descolonização e com especial dedicação ao que chamou de psicopatologia da colonização. 
ponto de vista do outro" a pessoa negra" (apud HALL, 2016, p. 160). Em vez disso, decisões precipitadas e julgamentos de valor foram tomados sob o olhar eurocêntrico, partindo da premissa de que a civilização europeia consistia no mais alto grau de evolução humana e devia ser almejado e copiado por todos. Sobretudo, Fanon (1968, p. 175) constata que o discurso colonial se torna influente inclusive no imaginário do próprio africano, ao se propor a convencê-lo de que o colonialismo iria "arrancá-los das trevas". A dominação de outros seres humanos almeja se legitimar frente a aceitação de que o ‘selvagem' não é um como nós.

Apenas mediante um conhecimento distorcido da realidade, amplamente difundido e consolidado, que atos de crueldade infligidos a outros seres humanos buscam ser justificados. Desta forma, o racismo se solidifica como pano de fundo no processo de rebaixamento e objetificação do outro, uma falha cognitiva que culmina em uma falha moral edificada nascida no cerne da sociedade européia e disseminada globalmente. Desde épocas coloniais, o outro vira espetáculo, não um ser humano em condição de igualdade como qualquer outro, mas um selvagem a ser menosprezado ou temido.

A própria noção de Oriente, assim como a de Ocidente, são construções sociais com o intuito de afirmar uma identificação, por oposição, de um 'eu' branco, civilizado, evoluído, superior; com 'o outro' negro, primitivo, atrasado, inferior. O crítico palestino Edward Said, em seus estudos sobre o Orientalismo, elucida que "existe, afinal, uma profunda diferença entre o desejo de compreender por razões de coexistência e de alargamento de horizontes, e o desejo de conhecimento por razões de controle e dominação externa" (SAID, 2007, p. 15). A Europa se utiliza de uma distinção valorativa com os 
povos por ela colonizados para reafirmar seus valores iluministas e justificar a exploração colonial.

Em 1969, após realizar uma conferência com especialistas internacionais, a (UNESCO) concluiu que "raça é menos um fenômeno biológico do que um mito social" (KI-ZERBO, 2010, p. 288) $)^{8}$. Ou como argumenta Hall (2013),

[...] raça é um dos principais conceitos que organiza os grandes sistemas classificatórios da diferença que operam em sociedades humanas. E dizer que raça é uma categoria discursiva é reconhecer que todas as tentativas de fundamentar esse conceito na ciência, localizando as diferenças entre as raças no terreno da ciência biológica ou genética, se mostraram insustentáveis. Precisamos, portanto - diz-se - substituir a definição biológica de raça pela sócio-histórica ou cultural.

Vale ressaltar que a tese de uma África em unicidade, definida como a terra dos negros, é algo construído por nãoafricanos e rejeitada por muitos habitantes do próprio continente. Appiah descreve que, quando Crummell lançou o livro The Future of África, em 1862, se utilizou de uma imagem de mundo aprendida nos Estados Unidos e Inglaterra capaz de falar "em nome de um continente" (APPIAH, 1997, p. 22). Segundo o filósofo, esta atitude estarreceu os nativos da Libéria. Mesmo parecendo irreal para os habitantes de terras africanas, o termo se popularizou mundialmente

8 Frente a enorme complexidade e, portanto, inconsistência de critérios para qualificar as raças, Livingstone já publicava, em 1952, seu artigo intitulado Da não existência das raças humanas. "Especialistas concluem, a partir daí, que "toda teoria das raças é insuficiente e mítica". "Os últimos progressos da genética humana são tais hoje em dia que nenhum biólogo admite a existência de raças na espécie humana"' (KI-ZERBO, 2010, p. 288). 
a ponto de por vezes ser confundido como 'um único país'. Em contrapartida, Appiah (1997, p. 38) afirma que os povos da África têm muito menos em comum, culturalmente, do que se costuma supor, e critica veementemente as consequências em se unificar os povos por um sentido de raça comum, que pressupõe uma unidade política natural que é, entretanto, inexistente.

Uma África concebida em termos raciais aceita a visão eurocentrada e o racismo implícito em sua concepção. Hountondji intitulou como "unanimismo" a compreensão "de que a África é culturalmente homogênea - à crença em que há uma espécie de corpo central da filosofia popular compartilhado pelos africanos negros em geral" (APPIAH, 1997, p. 48), e se dedicou a denunciar tal percepção equivocada. Desta forma, a extraordinária diversidade de etnias e culturas presentes em tão vasto território é obscurecida por generalizações empobrecedoras.

Por mais que pensar em uma África em seus atributos compartilhados possa ser proveitoso para os africanos em geral, consolidar sua base em uma unidade racial ou cultural mostrou ser um caminho inadequado. A questão central sobre o conhecimento consiste na necessidade em se problematizar os conceitos inerentes às formulações obtidas para que, em um segundo momento, seja possível aceitá-las ou rejeitá-las. Portanto, a questão não é que não se deva falar em nome da África, salvo a perder o que a força desta união ganharia em outros âmbitos. Apenas é preciso estar atento para não entrar no jogo ideológico de abstratas generalizações ou preceitos essencialistas. Para isso, então, é preciso descartar pressupostos de igualdade cultural ou histórica e assumir sua composição como um vasto, rico e diversificado continente. Como defende Hountondji 
(2008), África sim, mas por e para africanos.

\section{A Alternativa em Narrativas Híbridas, Autorais e Nativas nas Mídias Sociais}

Devido às possibilidades proporcionadas pelas novas mídias, descortinam-se áreas de atuação para um grupo infinitamente superior de fotógrafos em todo o mundo, ao mesmo tempo em que se ampliam as brechas para aquelas imagens que anteriormente não alcançavam repercussão pública por não se enquadrarem no que era requerido pela mídia tradicional. As redes sociais digitais ${ }^{9}$ dão autonomia ao fotógrafo em suas postagens autorais, sendo ele próprio o responsável por selecionar suas imagens e escrever suas legendas, quiçá, revolucionárias ${ }^{10}$. A constituição da mensagem fotográfica, então, ocorre de forma mais direta e sem tantas interferências externas em sua comunicação. Ao pensar no âmbito local, tais ferramentas facilitam a visualidade global de narrativas autorais composta por fotógrafos locais, denominadas aqui como narrativas nativas. Desta forma, em sintonia com a orientação proposta por Hountondji, fotógrafos documentaristas africanos, com suas vozes autorais e visões endógenas, produzem e compartilham nas redes sociais digitais novas narrativas sobre referenciais culturais e problemáticas sociais da vida no continente. Uma nova gama de visualidades e histórias construídas $n a$ e $d a$ África passam a habitar o imaginário coletivo e, assim, a disputar os sentidos do sistema de representação social consolidado.

9 Devido a sua ênfase no visual, o Instagram tem sido amplamente utilizado por fotógrafos de todos os cantos do planeta em busca de visibilidade global.

10 Há tempos Benjamin (2012, p. 138) já argumentava que deveria ser "do fotógrafo a capacidade de colocar em suas imagens legendas explicativas que as arranquem da clausura da moda e lhes confiram um valor de uso revolucionário" 


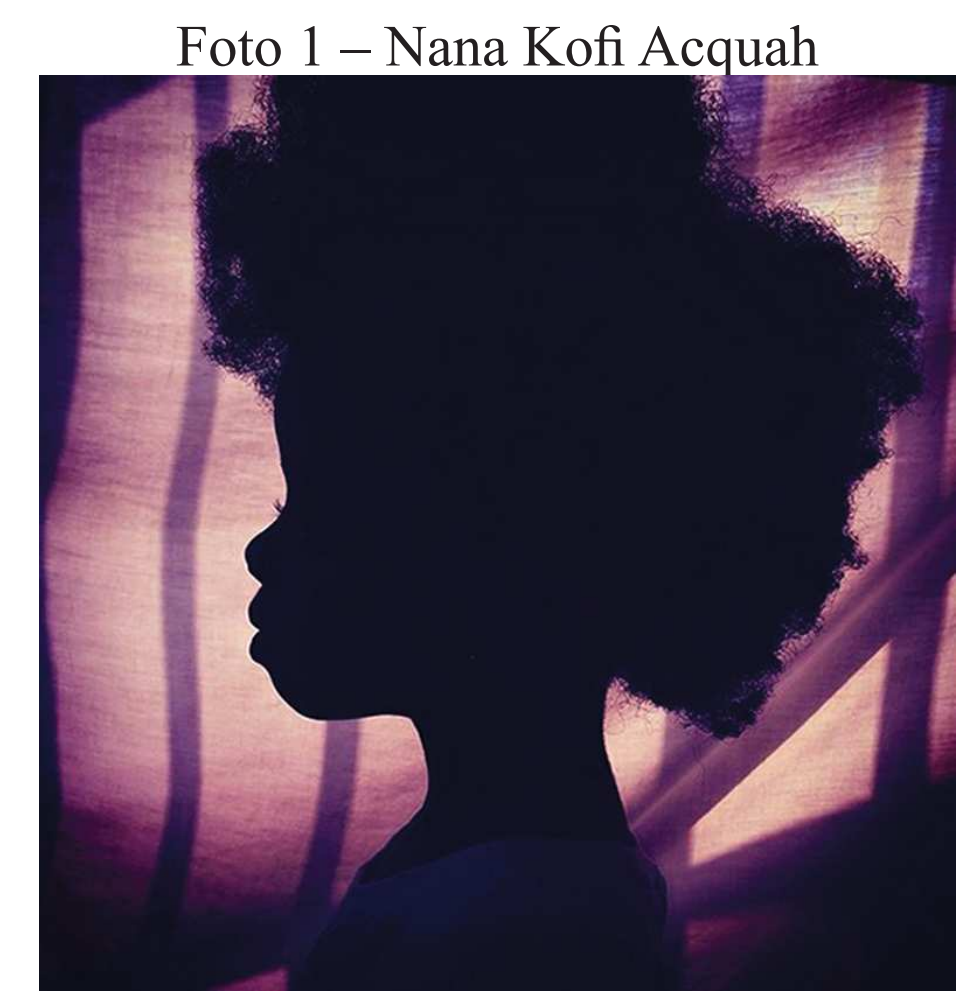

Legenda: "Afro on purple. Silhouette of my daughter. Accra, Ghana".

Fonte: Heijden et al. (2017, p. 335).

O fotógrafo ganês Nana Kofi Acquah costuma despertar a atenção através da expressividade de suas imagens - como a simples silhueta de sua filha em contraluz, um retrato com incrível força e beleza poética (Foto 1) que toca na especificidade da questão sobre os cabelos africanos - e vai além, provocando reflexões e debates através de suas legendas. "Nós não sabíamos que éramos "pobres" até que eles nos disseram" "11, declara o fotógrafo em outra postagem no perfil do projeto coletivo Everyday África no Instagram, no qual colabora ${ }^{12}$. 11 "We didn't know we were "poor" until they told us so". Fotografia e legenda complete disponível em: https://www.instagram.com/p/BB6rGnmjovx/?takenby=everydayafrica. Acesso em: 9 set. 2016.

12 Os fotógrafos aqui apresentados participam do Everyday África, um projeto coletivo que corporifica as discordâncias de fotojornalistas e documentaristas sobre a demandada da mídia internacional por representações estereotipadas em reportagens usualmente sobre a fome e a guerra no continente. Apesar do projeto se iniciar com um olhar predominantemente estrangeiro, com o passar dos anos e a soma de fotógrafos africanos à equipe de colaboradores efetivos, a proposta 


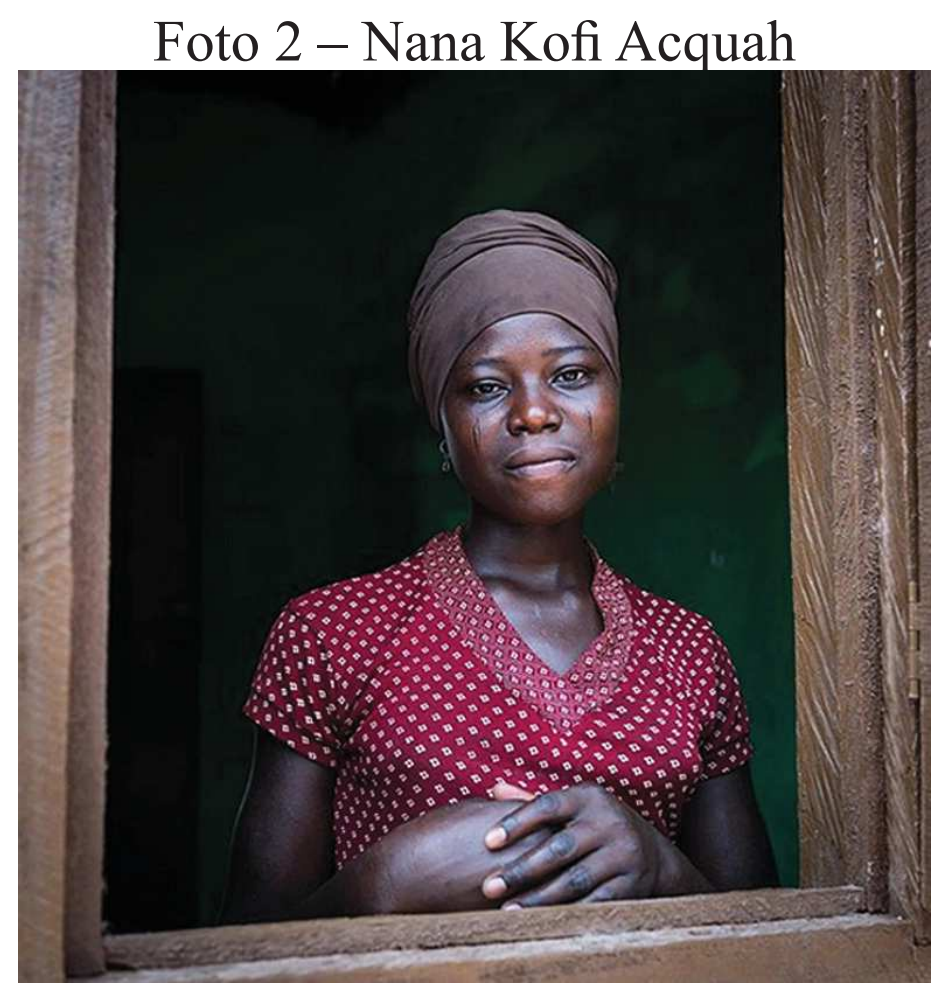

Legenda: "Beautiful is a bad word [...]".

Fonte: Instagram @Everydayafrica ${ }^{13}$.

$\mathrm{Na}$ soma de suas palavras, Acquah costuma contestar alguns mitos como o da pobreza ou da inferioridade africana pondo em xeque a forma como é construída a imagem do negro desde a colonização. Sua última exposição, Don't call me Beautiful, revela sua particular atenção à força - e não somente à beleza - das mulheres africanas, tema recorrente em seus retratos e sensível em suas imagens (Foto 2), onde busca promover uma visão que ultrapasse a superficialidade do belo e conduza a um mergulho em profundidade nas sensibilidades e na luta da vida da mulher na África.

Yagazie Emezi é uma jovem fotógrafa documental nigeriana.

se amplia e passa a revelar um olhar predominantemente endógeno que se utiliza das fotografias na rede para mostrar visualidades cotidianas e contar histórias sobre as especificidades da vida que se desenrola ao seu redor. Para o artigo foram escolhidos dois desses fotógrafos em algumas de suas imagens postadas no perfil do projeto no Instagram, sua principal, mas não exclusiva, área de atuação.

13 Disponível em: https://www.instagram.com/p/BiMMlpJAvQp/?takenby=everydayafrica. Acesso em: 18 ago. 2018 
Em seus retratos, Emezi se dedica a investigar a relação das pessoas com seu próprio corpo, em especial no conceito de beleza de mulheres empoderadas com seus incríveis penteados e coloridas vestimentas que se adornam ao seu bel prazer e, portanto, ignoram os padrões externos da moda. Seu recente projeto se inspira em Okhai Ojeikere, pioneiro na fotografia documental nigeriana, mundialmente conhecido por sua documentação dos incríveis penteados nigerianos.

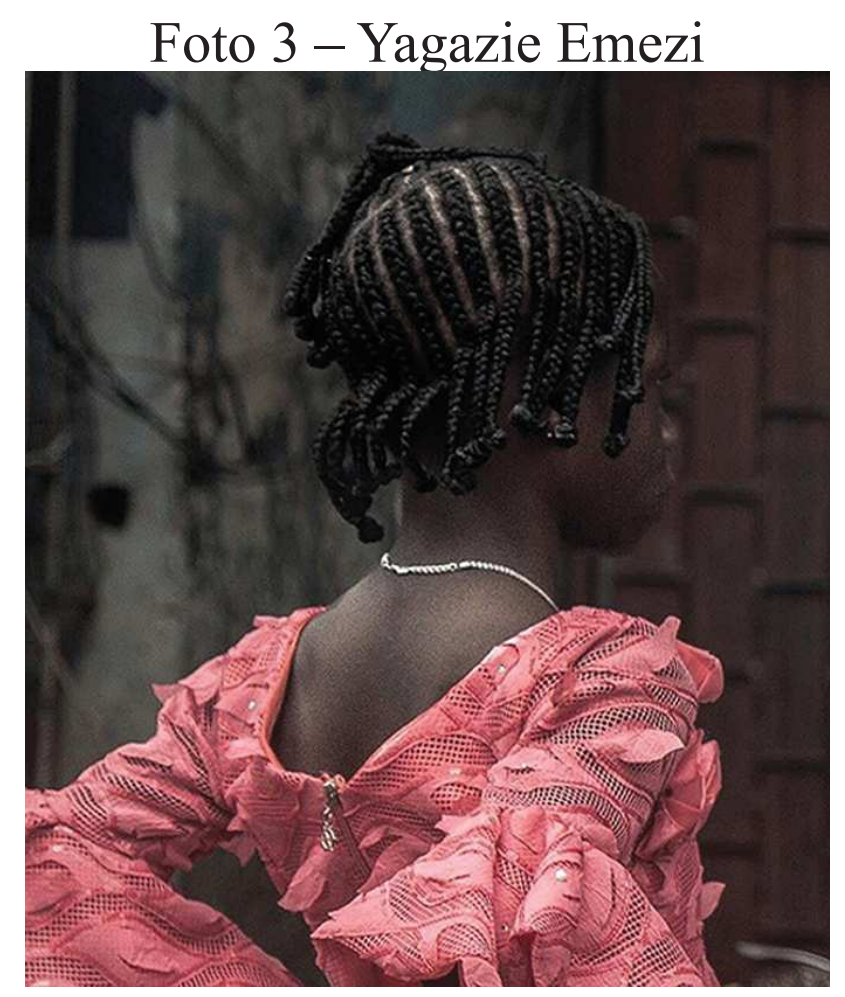

Legenda: “"“All these hairstyles are ephemeral... I always wanted to record moments of beauty, moments of knowledge." - Okhai Ojeikere".

Fonte: Instagram @Everydayafrica ${ }^{14}$.

$\mathrm{Na}$ legenda da imagem acima (Foto 3), Emezi reproduz as palavras de Ojeikere: "Todos esses penteados são efêmeros... Eu sempre quis gravar momentos de beleza, momentos de

14 Disponível em: https://www.instagram.com/p/BkQTaqZnISC/?takenby=everydayafrica. Acesso em: 18 ago. 2018 
conhecimento"15. Mais do que simples penteados, ambos fotógrafos reconhecem que tais práticas correspondem a traços da identidade cultural e da dinâmica social africana.

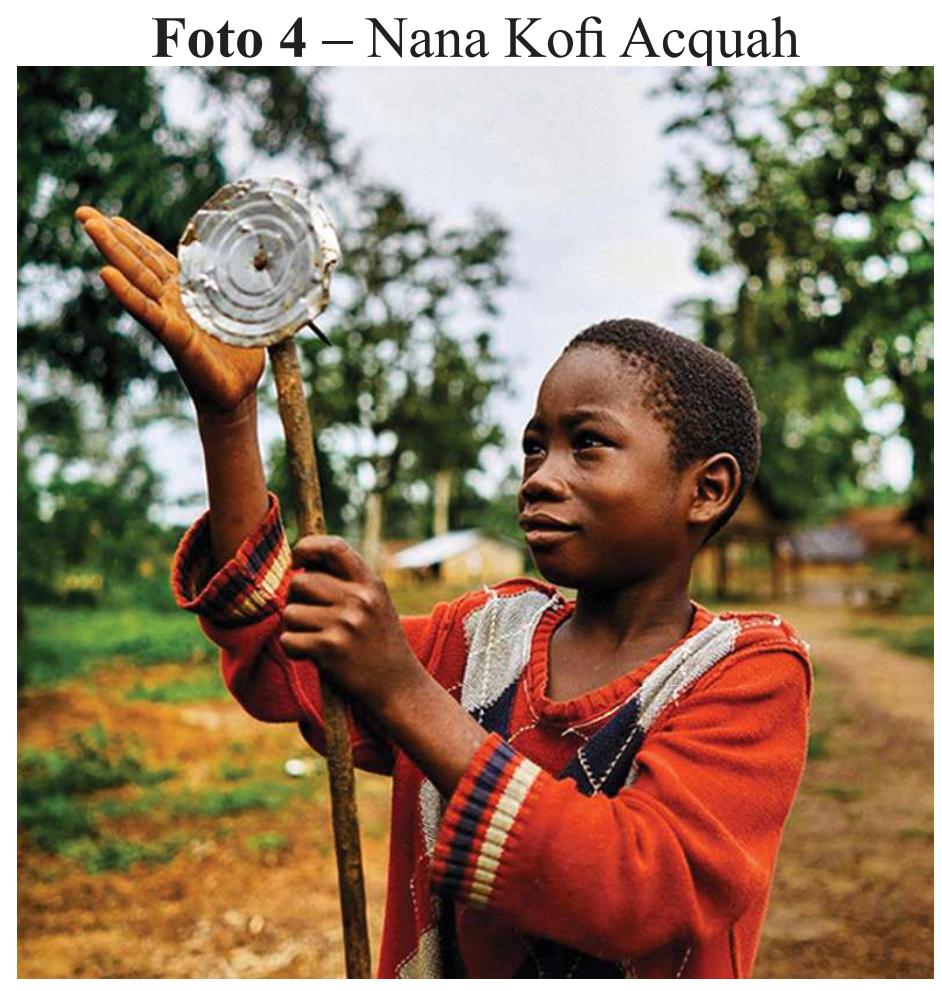

Legenda: "I met Surprise (his real name) playing with a toy he'd made himself. His confidence, joy, and curiosity was contagious. He lives in Otay Village, Grand

Bassa County, Liberia. Faraway from the prejudices of mass media and modern society. He's not yet aware that he's supposed to be disadvantaged, unintelligent, violent, criminal and a second class world citizen because of his skin colour. [...]".

Fonte: Instagram @EverydayAfrica ${ }^{16}$.

Segundo o argumento de Appiah, a penetração do colonizador em muitas das colônias europeias africanas foi essencialmente superficial. "Uma vez que provinham de culturas em que os negros

15 "“'All these hairstyles are ephemeral... I always wanted to record moments of beauty, moments of knowledge." - Okhai Ojeikere". Fotografia de Yagazie Emezi. Disponível em: https://www.instagram.com/p/BkQTaqZnISC/?takenby=everydayafrica. Acesso em: 18 ago. 2018

16 Disponível em: https://www.instagram.com/p/BHpWBmFgpvx/?takenby=everydayafrica. Acesso em: 18 abr. 2018. 
eram majoritários e em que a vida continuava a ser basicamente controlada por concepções morais e cognitivas locais, eles não tinham motivo para crer que fossem inferiores aos brancos" (APPIAH, 1997, p. 24). Efetivamente é uma falácia comum a muitos estrangeiros pensar que existe um peso nas pessoas que pertencem a "uma subcultura estigmatizada", obrigadas a "viver num mundo em que tudo, desde o seu corpo até sua língua, é definido pela "corrente dominante" como inferior" (APPIAH, 1997, p. 25). Falácia essa equiparável à visão construída e consolidada pelas notícias espetacularizadas na mídia de uma África resumida à guerra e à fome. Todavia, na medida em que o negro africano é de alguma forma obrigado a entrar em contato com tais construções pejorativas sobre o outro, o discurso da distinção colonial se faz presente, repleto de pressupostos de superioridade a padrões ocidentais de beleza e estilo de vida.

No retrato do menino Surprise (Foto 4), duas leituras são possíveis. O pobre coitado menino africano desprovido de recursos e oportunidades, ou o confiante, curioso e alegre Surprise. Segundo Acquah, o menino está distante dos preconceitos dos meios de comunicação massivos da sociedade ocidental e, portanto, ainda não foi afetado por valores que o desqualificam e subjugam apenas pela cor de sua pele.

O mesmo não ocorre com a personagem da fotografia de Emezi (Foto 5). A rejeição de sua cor de pele mais escura a impede de enxergar sua verdadeira beleza. A fotógrafa argumenta que entende suas inquietações, por partilhar dos mesmos ensinamentos e preceitos. Todavia, seus sentimentos e experiências dolorosas são únicos, e apesar de compreender, Emezi diz não compartilhar. "Eu 
olhei para ela antes e agora e ainda vi sua beleza brilhando"17. As práticas discursivas se tornam responsáveis por moldar, inclusive, formações identitárias no cerne do discurso (HALL, 2000, p. 109). E por muito tempo a narrativa depreciativa sobre os tons mais escuros da superfície das peles predominou.

Por mais que as experiências pessoais sejam singulares, pode haver uma maior compreensão ou mesmo cumplicidade ao se partilhar aprendizados históricos e saberes locais. As narrativas nativas detêm a marca do olhar endógeno, visível tanto em suas vivências e conhecimentos sobre crenças, hábitos e valores regionais, quanto no testemunho comprometido com as questões de sua localidade.

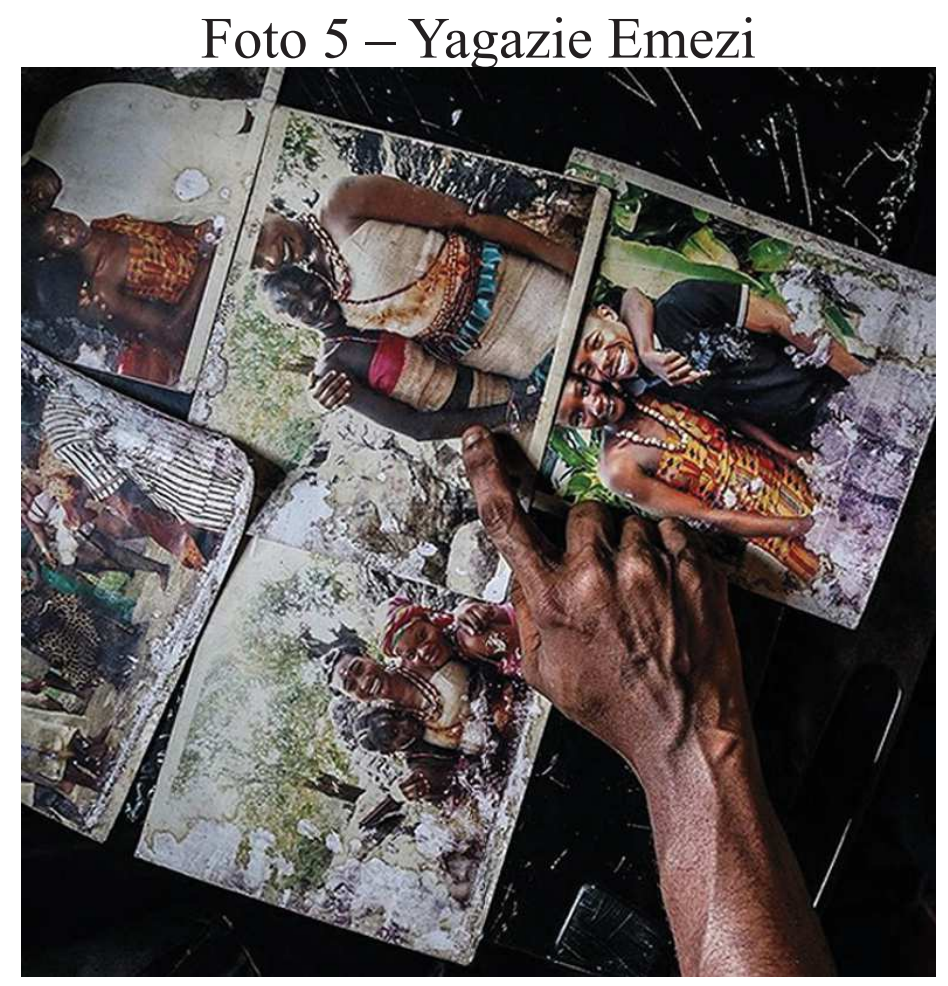

Legenda: "She pointed at her former, darker self. [...]". Fonte: Instagram@Everydayafrica ${ }^{18}$.

17 Disponível em: https://www.instagram.com/p/BKZHU9IAKeD/?takenby=everydayafrica. Acesso em 18 ago. 2018

18 Legenda completa disponível em: https://www.instagram.com/p/ BKZHU9IAKeD/?taken-by=everydayafrica. Acesso em: 18 ago. 2018. 
A vida cotidiana descortinada na cotidianidade da vida de seus fotógrafos nativos detém um misto de simplicidade e profundidade que potencializam suas histórias visuais. Pois a voz autoral desses documentaristas não se realiza somente ao criar e compartilhar imagens, mas igualmente em contar histórias. Como a de Hawa, uma jovem de 18 anos, e seu filho de 5, ambos frequentando a mesma escola (Foto 6). Emezi traz à tona a questão de meninas que se tornam vítimas de abuso, exploração sexual ou casamento precoce na Libéria, mas de uma forma suave e positiva ao enfatizar a presença de Hawa na escola pois, para muitas outras, o nascimento dos filhos significa o fim prematuro da educação.

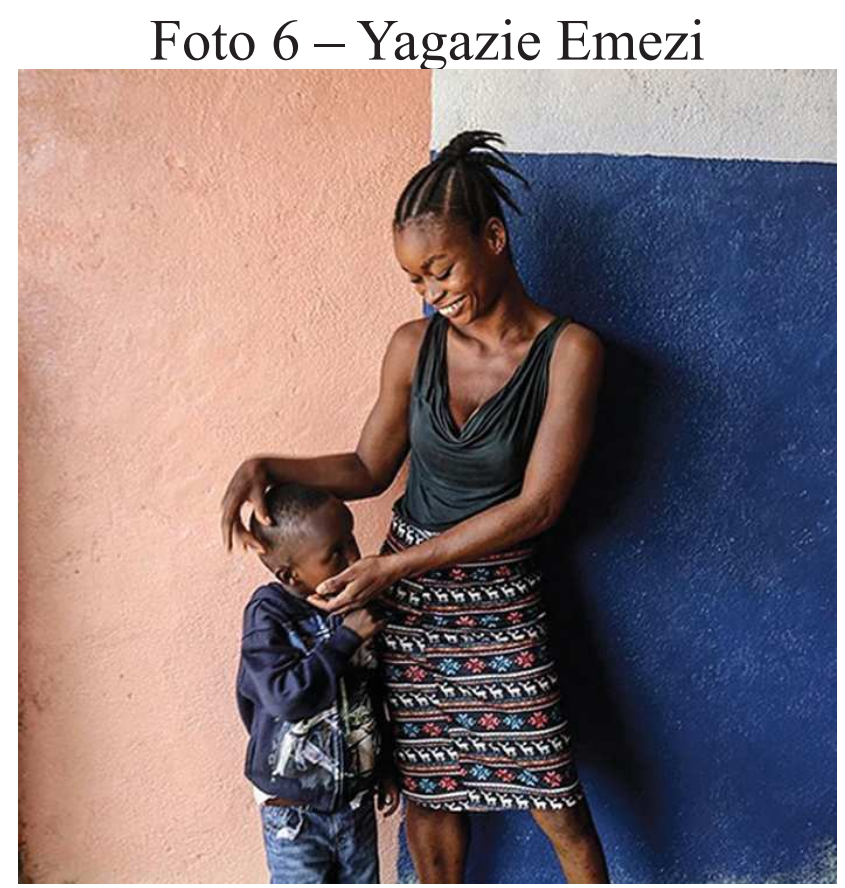

Legenda: "Hawa is 18 years old and is in the same school as her 5 year old son [...]". Fonte: Instagram @Everydayafrica ${ }^{19}$.

As histórias narradas em suas vozes e visões endógenas e autorais detém o poder de ir além da superfície aparente de imagens 19 Disponível em: https://www.instagram.com/p/BN1XKB5gwAN/?takenby=everydayafrica. Acesso em: 17 abr. 2018. 
e tons de pele para mergulhar mais profundo nas singularidades da vida ao redor. Em vozes que somam conteúdo às visões, as fotografias expressam sensações e contam histórias, revelam sorrisos e compartilham crenças, instigam reflexões e almejam conscientizar no debate junto ao público.

Já a predominância dos retratos no projeto realça a condição humana da vida na África. A multiplicidade de gestos, situações, cenários e histórias narradas, tanto dos fotógrafos nativos quanto dos nômades, enriquecem a percepção sobre um rico, vasto e diversificado continente, que tem muito a compartilhar.

\section{Considerações Finais}

A prática de registrar e compartilhar rostos, paisagens, feitos e sentimentos por meio de imagens técnicas conquistou lugar de prestígio na comunicação entre os homens, a ponto de tornar-se parte constituinte da vida cotidiana na contemporaneidade. Todavia, é preciso elucidar sobre os procedimentos constitutivos presentes nos discursos fotográficos, a começar por sua pretensa objetividade, e evoluir para a análise crítica das histórias por elas corroboradas. Os complexos processos que engendram os saberes sociais precisam ser tensionados criticamente em seus múltiplos contextos e configurações.

Igualmente, diante da inexistência de diferenciação biológica quanto a raça humana, o olhar sobre o outro precisa rejeitar as distinções valorativas e as estereotipias consolidadas nas únicas narrativas midiáticas e aceitar a premissa de que todos são iguais entre si. A partir desta concepção, e mediante as novas sensibilidades e histórias compartilhadas, é possível mergulhar nas especificidades 
culturais, sociais, econômicas e políticas de uma heterogênea e diversificada África. A multiplicidade de gestos, situações, cenários e histórias narradas tendem a enriquecer a percepção sobre um vasto e diversificado continente; seus retratos tendem a realçar a condição humana da vida na África, iluminando desde sentimentos universais a especificidades locais que ambicionam aproximar na semelhança entre os homens, mesmo que em meio a particularidades culturais. Vistas em conjunto, nas timelines das redes sociais digitais, fotografias heterogêneas revelam uma heterogênea África.

Por meio das narrativas nativas, torna-se possível compreender como um banho de bacia na rua, antes de ir para a escola, é uma vivência cultural e um momento memorável, não implicando em qualquer carência de provisões. Como o peso acima das cabeças femininas, carregados com charme e desenvoltura, traduz a força e a dignidade das mulheres africanas. E a criança que ajuda a mãe nas compras da feira não deve ser imediatamente percebida e julgada por olhares externos como uma criança pobre, fora da escola, vítima de trabalho infanti1 ${ }^{20}$.

Embora Hall alerte para o fato de que apenas a adição de imagens positivas não seja, talvez, suficiente para que se desloque uma percepção negativa já pré-existente; não é mais de uma única tipologia de histórias que se compõe a visualidade sobre a África. Diante nas novas mídias, a alternativa das narrativas nativas passam a habitar gradativamente as redes sociais digitais à espera de que espectadores

20 Estas são reflexões retiradas da análise de outras fotografias do projeto

Everyday África, objeto de estudo de dissertação de mestrado intitulada “A Voz dos Fotógrafos: Uma Análise da Função Pública e da Potência Política da Fotografia Documental em Cenas da Vida Cotidiana no Everyday África", pelo PPGMC-UFF, 2016-18. 
64 Para além da superfície da imagem: disputa de narrativa por fotógrafos da África

globais efetivamente mergulhem em outras versões da história.

\section{Referências}

ADICHIE, Chimamanda Ngozi. Para educar crianças feministas: um manifesto. São Paulo: Companhia das Letras, 2017.

ADICHIE, Chimamanda Ngozi. The danger of a single story. In: TED GLOBAL CONFERENCE, 2009, Oxford, UK. Palestra proferida [...]. Oxford: TED Global, 2009. Speakers. Disponível em: https://www.ted.com/talks/chimamanda_adichie_the_danger of_a_single_story/transcript. Acesso em: 15 nov. 2017.

APPIAH, Kwame Anthony. Na casa de meu pai: a África na filosofia da cultura. Rio de Janeiro: Contraponto, 1997.

BENJAMIN, Walter. Magia e técnica, arte e política: ensaios sobre literatura e história da cultura. São Paulo: Brasiliense, 2012. (Obras Escolhidas, v. 1).

DUBOIS, Philippe. O ato fotográfico. Campinas, SP: Papirus, 1993.

EVERYDAY AFRICA. Perfil no Instagram. Disponível em: https:// www.instagram.com/everydayafrica/. Acesso em: 6 nov. 2016. FANON, Franz. Os condenados da Terra. Rio de Janeiro: Editora Civilização Brasileira, 1968.

HALL, Stuart. Cultura e representação. Rio de Janeiro: Ed. PUCRio: Apicuri, 2016.

HALL, Stuart. Quem precisa de identidade? In: SILVA, Tomaz Tadeu da (org.). Identidade e diferença: a perspectiva dos estudos culturais. Petrópolis, RJ: Vozes, 2000.

HALL, Stuart. Raça, o significante flutuante. Revista Z Cultural, 
Rio de Janeiro, RJ, Ano 8, n. 2, 2013. versão online. Disponível em: http://revistazcultural.pacc.ufrj.br/raca-o-significanteflutuante $\% \mathrm{EF} \% 80 \% \mathrm{AA} /$. Acesso em: 14 jul. 2018.

HALL, Stuart. The determinations of news photographs. In: COHEN, Stanley; YOUNG, Jock (org.). The manufacture of news: social problems, deviance and the mass media. London: Constable, 1981. p. 226-243.

HEIJDEN, Teun Van Der; DICAMPO, Peter; MERRILL, Austin ACQUAH, Nana Kofi (ed.). Everydayafrica: 30 photographers repicturing a continent. Berlin: Kehrer Heidelberg, 2017.

HOUNTONDJI, Paulin J. Conhecimentos de África, conhecimento de africanos: duas perspectivas sobre os estudos africanos. Revista Crítica de Ciências Sociais, Coimbra, PT, n. 80, p. 149-160, mar. 2008. Disponível em: https://filosofia-africana.weebly.com/ uploads/1/3/2/1/13213792/paulin_hountondji___conhecimentos de_\%C3\%81frica_conhecimento_de_africanos._duas_perspectivas sobre_os_estudos_africanos.pdf. Acesso em: 4 jul. 2018.

KI-ZERBO, Joseph (ed.). História geral da África. Metodologia e pré-história da África. Brasília: UNESCO, 2010. v. 1.

SAID, Edward W. Orientalismo: o Oriente como invenção do Ocidente. São Paulo: Companhia das Letras, 2007.

SEKULA, Allan. On the invention of photographic meaning. In: BURGIN, Victor (org.). Thinking photography. London: Macmillan Press, 1982. p. 84-109.

SEKULA, Allan. Photography against the Grain. Nova Scotia: The Press of the Nova Scotia College Art and Design, 1984. 